
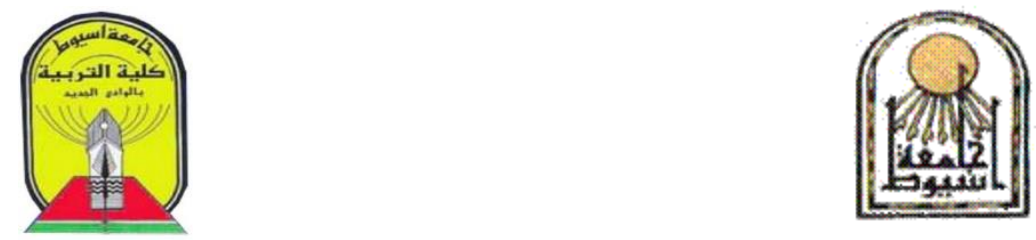

كلية التربية بالوادي الجديد

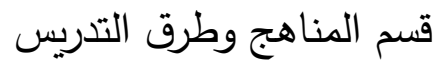

فاعلية تدريس وحدة اثرائية في الكيمياء باستخدام استراتيجية الويب كويست لاستيعاب بعض مفاهيم كيمياء النانو والاتجاه نحو التعلم الإكتروني لاى طلاب الصف الأول الثانوي رسالـة مقدمة من محمد مصطفى محمد خليفة مقدم برامج بإذاعة الوادى الجديد للحصول على درجة الماجستير في التربية تخصص المناهج وطرق تدريس العلوم إثــراف أ.د / عمر سيد خليل استاذ المناهج وطرق تدريس العلوم كلية التربية جامعة اسيوط

د/ شرين شحاتة عبد الفتاح دادمادة تراشر لوندى مدرس المناهج وطرق تدريس العلوم مدرس المناهج وطرق تدريس العلوم كلية التربية بالوادي الجديد كلية التربية بالوادي الجديد

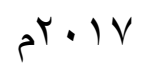


فاعلية تدريس وحدة اثرائية في الكيمياء باستخدام استراتيجية أ. محمد مصطفى محمد

مقدمة

تتثكل المفاهيم الكيميائية على هيئة أبنية ذهنية تتكون لدى المتعلم نتيجة لإدراكه للمعاني والصور والحقائق ذات الصلة بالظواهر والأحداث الطبيعية. لذلك لا تتم عملية إنماء المفاهيم الكيميائية بمجرد تقديم المفهوم أو دلالته اللفظية، بل تقتضي تخطيطا في والي التدري يتضمن تتظيما متكاملا للمعرفة العلمية والمواقف التعليمية والمقارنة بينها ثم تصنيفها والوصول إلى تكوين المفهوم واكتسابه. ونظرا لما شهده علم الكيمياء من انفجارًا في المحتوى بصورة تفوق قدرتنا على التصور ، فظهرت العديد من المفاهيم الكيميائية المعاصرة في مجالاته وأفرعه المختلفة مثل الكيمياء الخضراء وكيمياء الفيمتو وكيمياء الأنسجة وكيمياء النانو وغيرها.

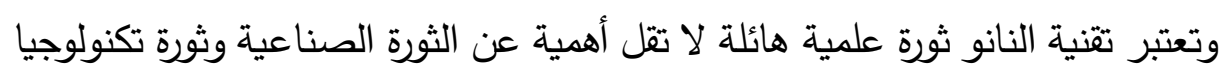

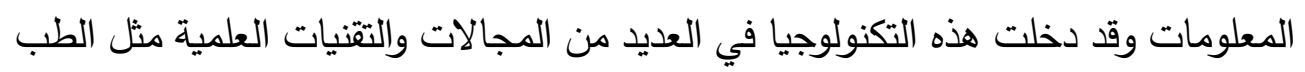
وعالم الإكتروني ات وعالم البناء وغيرها، وعليه بات ضروريا على مؤسساتتا التعليمية

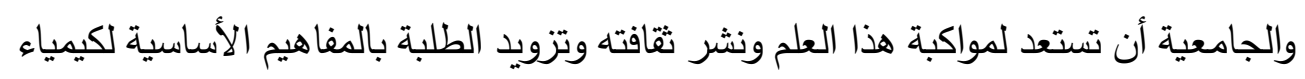
النانو.

وبذلك يعد الاستيعاب المفاهيمي لهذه المفاهيم الحديثة هدفاً رئيساً من أهداف تعليم وتعلم العلوم حيث يمكّن الاستيعاب المفاهيمي الأفراد من نقل معارفهم من الظروف التي لتهي تعلموا بها إلى الأوضاع الجديدة، وتسمح لهم بالتكيف مع الظروف المتغيرة. وحتى يتمكن المعلم من تحقيق هذا الهدف لابد من استخدام الاستراتيجيات والتقنيات الحديثة وتوظيفها. وتعتبر استراتيجية الويب كويست إحدى الاستراتيجيات التي تستخدم التقنيات الحديثة وتوظفها في عملية التعلم، فهي إحدى التطبيقات التكنولوجية المستتدة على الإنترنت، والتي فيها يتبع الطلاب خطوات محددة وفقا لأنشطة موجهة تسمح لهم باستخدام الإنترنت للحصول على المعرفة الجديدة وتطبيقها لإنهاء مهمة محددة حول موضوع معين. 


\section{مشكلة الدراسة}

تتمثل مشكلة الدراسة الحالية في السؤال البحثي الرئيسي الآتي: " ما فاعلية تدريس وحدة إثراءيه في الكيمياء باستراتيجية الويب كويست في استيعاب بعض مفاهيم كيمياء النانو؟ "

ويمكن حل تلك المشكلة من خلال الإجابة عن التساؤلات الآتية: 1 ـ ما مفاهيم كيمياء النانو التي سيتم اثراء الوحدة بها r. ما التصور المقترح لاستراتيجية الويب كويست لتدريس وحدة إثراءيه في الكيمياء لطلاب الصف الأول الثانوي؟ r. ما فاعلية تدريس الوحدة الإثرائية باستراتيجية الويب كويست في استيعاب بعض مفاهيم كيمياء النانو لاى طلاب الصف الأول الثانوي؟ ـ. ما فاعلية تدريس الوحدة الإثرائية باستراتيجية الويب كويست في تتمية الاتجاه

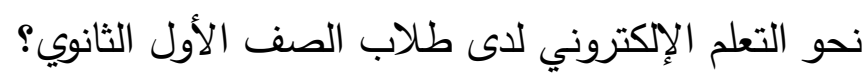
๑. هل يوجد فرق ذو دلاله احصائية بين متوسطي درجات الطلاب البنين والبنات

$$
\text { (عينة الدراسة) في الاختبار البعدي؟ }
$$

7 ـ هل يوجد فرق ذو دلاله احصائية بين متوسطي درجات الطلاب البنين والبنات (عينة الدراسة) في مقياس الاتجاه نحو التعلم الإلكتروني؟

أهداف الدراسة :

تهدف الدراسة الحالية إلى ما يلي:

ا ـ إعداد وتصميم وحدة إثراءيه باستراتيجية الويب كويت لتدريس الكيمياء بهدف استيعاب بعض مفاهيم كيمياء النانو طلاب الصف الأول الثانوي. r. الكثف عن مدى فاعلية استراتيجية الويب كويست في تدريس الوحدة الإثرائية في استيعاب بعض مفاهيم كيمياء النانو. 


\section{فاعلية تدريس وحدة اثرائية في الكيمياء باستخدام استراتيجية أ. محمد مصطفى محمد}

r. الكثف عن مدى فاعلية استراتيجية الويب كويست في تدريس الوحدة

$$
\text { الإثرائية في تتمية الاتجاه نحو التعليم الإككترني. }
$$

ع. التحقق من الفروق بين البنين والبنات في استيعابهم لمفاهيم كيمياء النانو

نتيجة لتعرضهم لدراسة الوحدة الاثرائية المقترحة باستخدام استراتيجية الويب

$$
\text { كويست. }
$$

ه. التحقق من الفروق بين البنين والبنات في الاتجاه نحو التعليم الإكتروني.

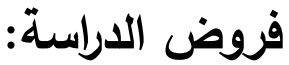

تسعى الدراسة الحالية إلى التحقق من الفرضان التاليان:

ا . يوجد فرق ذو دلالة إحصائية بين متوسط درجات المجموعة التجريبية في

التطبيقين القبلي والبعدي لاختبار استيعاب مفاهيم كيمياء النانو.

r . يوجد فرق ذو دلالة إحصائية بين متوسط درجات المجموعة التجريبية في

التطبيقين القبلي والبعدي في مقياس الاتجاه نحو التعلم الإكتروني.

r. يوجد فرق ذات دلالة إحصائية بين متوسطي درجات الطلاب البنين والبنات

$$
\text { (عينة الدراسة) في الاختبار البعدي. }
$$

ع. يوجد فرق ذات دلالة إحصائية بين متوسطي درجات الطلاب البنين والبنات

(عينة الدراسة) في مقياس الاتجاه نحو التعلم الإلكتروني في التطبيق

$$
\text { أدوات الدراسةة: }
$$

يقوم الباحث بإعداد الأدوات التالية:

ا. قائمة مفاهيم كيمياء النانو المراد تتمية استيعابها

$$
\text { r. r. موقع الويب كويست. }
$$




$$
\begin{aligned}
& \text { ع. اختبار استيعاب مفاهيم كيماء النانو. } \\
& \text { ه. مقياس الاتجاه نحو التعلم الإكتروني. } \\
& \text { عينة الدراسة: }
\end{aligned}
$$

تكونت عينة الدراسة من طلاب الصف الأول الثانوي بمحافظة الوادي الجديد، وكان عددهم(7^) طالب وطالبة من مدرستين من مدارس مركز الخارجة (مدرسة الخارجة الثانوية بنين ونجيب محفوظ الثانوية بنات) ليمثلوا المجموعة التجريبية.

\section{متغيرات الدراسة:}

المتغير المستقل: وحدة إثراءيه مقترحة تدرس باستراتيجية الويب كويست. المتغير التابع: - استيعاب بعض مفاهيم كيمياء النانو والاتجاه نحو التعلم

$$
\text { منهج الاراسة: الإكتروني. }
$$

تستخدم الدراسة الحالية:

- - المنهج شبه التجريبي للتأكد من فاعلية تدريس الوحدة الإثرائية المقترحة باستخدام استراتيجية الويب كويست على تتمية استيعاب مفاهيم كيمياء النانو لدى عينة من طلاب الصف الأول الثانوي.

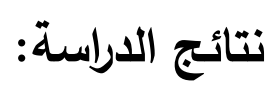

ا. وجود فروق ذات دلالة إحصائية عند مستوى الدلالة ( ( .... ) بين التطبيق القبلي والبعدي للمجموعة التجريبية في اختبار الاستيعاب المفاهيمي لمفاهيم كيمياء النانو التي درست الوحدة الإثرائية باستراتيجية الويب كويست لصالح التطبيق البعدي. 
فاعلية تدريس وحدة اثرائية في الكيمياء باستخدام استراتيجية أ. محمد مصطفى محمد

Y. وجود فروق ذات دلالة إحصائية عند مستوى الدلالة (1 +.,. •) بين التطبيق القبلي والبعدي للمجموعة التجربية في مقياس الاتجاه نحو التعلم الإكتروني التي درست الوحدة الإثرائية باستراتيجية الويب كويست لصالح التطبيق البعدي r. عدم وجود فرق ذو دلالة إحصائية بين متوسطي درجات الذكور والإناث في التطبيق البعدي لاختبار استيعاب مفاهيم كيمياء النانو. ع. عدم وجود فرق ذو دلالة إحصائية بين متوسطي درجات الذكور والإناث في التطبيق البعدي لمقياس الاتجاه نحو التعلم الإلكتروني.

\section{توصيات الدراسة:}

ا. إجراء دورات تدريبية، لتدريب المعلمين أثناء الخدمة على تطبيق استراتيجية الويب كويست داخل الصف في تدريس الكيمياء بصفة خاصة، والمواد الدراسية بصفة عامة.

r. عمل حقيبة تدريبية تتضمن خطوات تتفيذ استراتيجية الويب كويست لكل مرحلة دراسية والاستفادة منها في تدريب المعلمين المبتدئين. r. التركيز على تتمية المستويات المختلفة للاستيعاب المفاهيمي لدى الطلاب في المراحل العمرية المختلفة ومتابعة تطور تلك المستويات باستمرار .

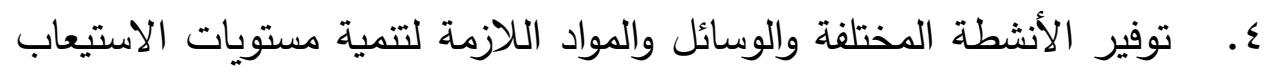
المفاهيمي التي لم تحظى بقدر وافر من الاهتمام من قبل الطلاب وإعطائها الأولوية. ه. توفير بيئة تعليمية صفية ومدرسية تمكن الطلاب من استيعاب المفاهيم العلمية في المواد الدراسية المختلفة وكذلك تقلل من القلق والتوتر والخوف من الفشل وتتمي لايهم الاتجاه نحو تحصيلهم. 
7. الحرص أثناء تخطيط مناهج العلوم عامة بحيث تركز أهدافها، وأساليب تدريسها

على استيعاب المفاهيم العلمية المعاصرة (مثل مفاهيم كيمياء النانو) ليتواكب

$$
\text { مقترحات الاراستة: مع تطورات العصر وذلك من خلال استراتيجيات حديثة في التدري. }
$$

ا ـ دراسة فاعلية استخدام استراتيجية الويب كويست في تتمية مهارات التفكير العليا لدى طلاب المرحلة الثانوية.

r. دراسة فاعلية استخدام استراتيجية الويب كويست في الاستيعاب المفاهيمي لاى طلاب المرحلة الجامعية.

r. دراسة فاعلية استخدام الخرائط الذهنية الإلكترونية في استيعاب المفاهيم الكيميائية المعاصرة.

ـ. دراسة فاعلية برنامج مقترح في الكيمياء لتنمية المفاهيم الكيميائية المعاصرة لاى طلاب المرحلة الإعدادية. ه. دراسة فاعلية استخدام استراتيجية الويب كويست في تتمية مهارات الذكاء المنطقي والرياضي في تدريس الرياضيات. 